\section{Física e literatura: construindo uma ponte entre as duas culturas}

\author{
Physics and literature: \\ building a bridge \\ between two cultures
}

ZANETIC, J.: Física e literatura: construindo uma ponte entre as duas culturas.

História, Ciências, Saúde - Manguinhos, v. 13 (suplemento), p. 55-70, outubro 2006.

Este artigo defende a aproximação entre física e literatura como uma forma útil de interpretar o mundo. Utilizo nessa aproximação a filosofia de Gaston Bachelard, explorando sua discussão sobre perfis epistemológicos em que comparecem doutrinas filosóficas que vão do realismo ingênuo ao ultraracionalismo, compreendendo entre elas o empirismo determinista da física clássica e a indeterminação da física contemporânea. Destaco estas últimas porque analiso, de forma metafórica, os perfis epistemológicos de alguns escritores importantes do século XIX e início do século XX que são exemplos de transição entre aquelas duas doutrinas filosóficas. A ponte aqui será mais explicitamente a transformação do papel do escrito literário na passagem da visão de mundo influenciada pela física clássica, representada pelos escritores Edgar Allan Poe, Gustave Flaubert, Emile Zola e Augusto Zaluar, para aquela que nasceria influenciada pela física contemporânea, exemplificada pelos escritos de Fiódor Dostoiévski e William Faulkner.

PALAVRAS-CHAVE: física e literatura; ensino de física; interdisciplinaridade; filosofia da ciência.

ZANETIC, J.: Physics and literature: building a bridge between two cultures História, Ciências, Saúde - Manguinhos, v. 13 (supplement), p. 55-70, October 2006.

In this article, I advocate linking physics and literature as a useful way of interpreting the world. To this end, I use the philosophy of Gaston Bachelard and his discussion of "epistemological profiles," which embrace philosophical doctrines running the gamut from naïve realism to ultrarationalism while also including the determinist empiricism of classical physics and the indetermination of contemporary physics. Special attention is drawn to the latter two as I undertake a metaphorical analysis of the epistemological profiles of some major nineteenth-and earlytwentieth-century writers who exemplify the transition between the two philosophical doctrines. On one end of this transformational bridge was the literary writing style that conveyed a worldview influenced by classical physicsrepresented by Edgar Allan Poe, Gustave Flaubert, Emile Zola, and Augusto Zaluar-and on the other, a writing style born under the influence of contemporary physics, found in the writings of Fyodor Dostoyersky and William Faulkner.

KEYWORDS: physics and literature; the teaching of physics; interdisciplinarity; philosophy of science. 
Oinos - Mas eu sonhei que nesta existência ficaria imediatamente conhecedor de todas as coisas e tornar-me-ia, assim, imediatamente feliz por conhecer tudo.

Agathos - Ah! A felicidade não está no conhecimento, mas na aquisição do conhecimento! Sabendo para sempre, seremos para sempre venturosos; saber tudo, porém, seria diabólica maldição.

Edgar Allan Poe (1966, p. 429)

$\mathrm{P}$ ode parecer estranha minha insistência na tentativa de aproximar a física e a literatura, duas áreas do conhecimento aparentemente tão distintas e antagônicas que chegam a ser alvo de uma polêmica entre as duas culturas (Snow, 1997). Recentemente, num seminário vinculado a esse tema, ouvi o seguinte alerta de um colega: "Você está querendo trabalhar com duas disciplinas odiadas pelos alunos". Reconheço a realidade dessa advertência, mas recuso-me a aceitá-la. É claro que devemos pensá-las e pesquisálas isoladamente nas suas especificidades. Há os que preferem uma delas e outros a outra. Mas creio que na contemporaneidade só temos a ganhar se aproximarmos as duas.

Em função do impacto que as ciências exatas provocaram na face do mundo contemporâneo, é natural que haja uma valorização na difusão do pensamento científico. Em 2005 homenageou-se a inventividade de Albert Einstein (1879-1955) e a influência de suas idéias na ciência, tecnologia, arte, política e religião. Não devemos reforçar uma visão de mundo que supervalorize o pensamento científico em detrimento de outras formas de saber e conhecer. Se não podemos mitificar a figura de Einstein como um gênio da física (Martins, 2005), menos ainda devemos fazê-lo em suas incursões por outras áreas do conhecimento.

É importante valorizar as citações de Einstein, por exemplo, como um grande físico, mas somente no que diz respeito aos seus trabalhos em eletrodinâmica ou relatividade e não considerá-lo um 'gênio' em todo e qualquer assunto, como em política, economia ou estratégia militar. (Pinto, 2003, p. 87)

No entanto, sempre aprendi muito por meio da leitura das grandes obras de cientistas, romancistas, poetas, filósofos e historiadores, mesmo quando distantes de suas especialidades mais específicas, não como se fossem "donos da verdade", mas como indivíduos de extrema sensibilidade que produziram reflexões que podem nos auxiliar no diálogo inteligente com o espaço-tempo em que vivemos. É com essa intenção que eu gostaria que este texto fosse entendido. 


\section{As duas culturas}

Essa aparente incongruência em procurar associar ciência e arte foi abordada por diversos autores, alguns contrários e outros favoráveis a essa aproximação. Obviamente incluo-me entre estes últimos, acreditando que a contaminação mútua entre essas duas culturas é útil não apenas para interpretar o mundo, mas também para transformá-lo, como ensinava Karl Marx.

O educador francês Georges Snyders recorria à leitura e análise de obras literárias que haviam estado presentes em sua vida, para discutir tristezas e alegrias na escola. Nessa busca, ele acabou concluindo que pode ser construída uma aproximação entre tais obras e as ciências. Ele destacava o papel das obras-primas da literatura universal como fontes geradoras de reflexão e conhecimento (Snyders, 1993).

Jacob Bronowski (1908-1979), cientista e divulgador da ciência que muito escreveu sobre esse tema, também defendia tal aproximação. Ele argumentava que tanto a ciência como a literatura, embora utilizando caminhos que lhes são peculiares, nos fornecem conhecimento universal. Bronowski utilizava, em particular, seu entendimento sobre a imaginação - manipulação das imagens que um ser humano tem na cabeça - para estabelecer sua ponte entre ciência e literatura:

A imaginação nos atinge e nos penetra de formas diferentes na ciência e na poesia. Na ciência, ela organiza nossa experiência em leis, sobre as quais baseamos nossas ações futuras. A poesia, porém, é outro modo de conhecimento, em que comungamos com o poeta, penetrando diretamente na sua experiência e na totalidade da experiência humana. (Bronowski, 1998, p. 20)

Atualmente essa temática volta a ter força teórica e prática envolvendo os mais variados aspectos e conteúdos, ora enfatizando a presença da ciência na literatura, ora analisando possíveis previsões científicas praticadas por grandes escritores: os escritores com veia científica e os cientistas com veia literária. Um exemplo recente é a proliferação de textos para teatro que abordam temas relacionados à física, como é o caso das peças Einstein e Copenhagen, que alcançaram sucesso no Brasil na interpretação do grupo "Arte e Ciência no Palco". Philip Ball, até há pouco tempo editor de ciências físicas da revista Nature, destaca que, além do conteúdo científico traduzido por meio de palavras, também as imagens geradas pela física podem ser exploradas no contexto dramático. É o caso da experiência de Newton de decomposição da luz branca por prismas, ou da experiência dos Curie envolvendo a luminosidade emanada da solução de rádio. 
A ciência está se tornando cada vez mais presente no teatro, onde é vista como uma fonte de idéias e metáforas. Acredito que não devemos descuidar do potencial da ciência como uma fonte abundante de imagens mentais para o teatro. A pesquisa científica pode prover novas linguagens físicas para a expressão teatral e novos modos de examinar e representar o mundo. (Ball, 2002, p. 169)

Num artigo recentemente publicado examino a aproximação entre física e cultura na escola, no contexto social e na literatura (Zanetic, 2005). Noutro artigo exploro a possibilidade de se utilizarem letras de música e textos literários no ensino de física (Zanetic, 2006). O físico e divulgador da ciência Ildeu de Castro Moreira selecionou poemas de poetas brasileiros como forma de enriquecer atividades interdisciplinares em aulas de ciências:

Ciência e poesia pertencem à mesma busca imaginativa humana, embora ligadas a domínios diferentes de conhecimento e valor ... $\mathrm{Na}$ origem desses dois movimentos, as incertezas de uma realidade complexa que demanda várias faces que podem transformarse em versos, em gedankens ou ser representados por formas matemáticas. (Moreira, 2002, p. 17)

Exploro neste artigo outras implicações da aproximação entre física e literatura, em particular aquela referente à utilização de embasamentos epistemológicos por escritores de diferentes épocas. Assim, serão personagens deste artigo escritores com veia científica aos quais podemos associar uma ou outra das versões epistemológicas identificadas na construção de teorias científicas. Utilizo nessa aproximação a análise desenvolvida por Gaston Bachelard (1884-1962), que estudou tanto a epistemologia da ciência como o discurso poético e literário.

\section{Questões epistemológicas}

Bachelard contrapunha o espírito científico característico do pensador diurno que trabalha com conceitos ao espírito poético característico do pensador noturno que trabalha com imagens. No entanto, ele reconhecia ser possível revelar os segredos do mundo, ou seja, construir conhecimento, não só através de conceitos científicos mas também através de imagens poéticas e literárias. O denominador comum que une a produção intelectual desses dois pensadores é a ruptura com o aparente. Para o pensador diurno seria a ruptura com os obstáculos epistemológicos.

Outra contribuição de Bachelard para a análise do discurso nas ciências é seu estudo sobre os perfis epistemológicos apresentados por indivíduos que refletem sobre determinados conceitos científicos, como massa, energia, espaço-tempo e complementaridade, por exemplo. 
Quando analisou sua compreensão do conceito de massa, por exemplo, ele destacou várias doutrinas filosóficas presentes no seu perfil epistemológico:

Quando nós próprios nos interrogamos, damo-nos conta de que as cinco filosofias que considerámos (realismo ingénuo - empirismo claro e positivista - racionalismo newtoniano ou kantiano racio-nalismo completo [relatividade] - racionalismo dialético) orientam em direcções diversas utilizações pessoais da noção de massa. (Bachelard, 1972, p. 57)

Na construção do perfil epistemológico estão presentes continuidades e rupturas associadas a noções conceituais, concepções metodológicas e hábitos e práticas da vida cotidiana. Isso fica claro quando Bachelard descreve as filosofias presentes no seu perfil epistemológico do conceito de massa. Embora nele predomine a noção racionalista de massa, gerada por anos de prática no ensino elementar, estão ainda presentes, no lado "mais pobre da cultura", o empirismo derivado de anos de trabalho como funcionário dos Correios e em laboratórios de química sob a "conduta da balança" e, no lado cultural mais rico, as noções derivadas da relatividade e da mecânica quântica.

Bachelard sempre se preocupava em não enfatizar exageradamente uma filosofia em detrimento das outras, ou seja, ele destacava a continuidade e a ruptura entre diferentes concepções epistemológicas, entendendo que mesmo as "filosofias sãs" poderiam se transformar em obstáculos epistemológicos (Bachelard, 1972, p. 59).

Esse obstáculo epistemológico transforma-se também num obstáculo pedagógico, quando atentamos para a forma dominante de exposição dos conteúdos científicos nos textos didáticos, particularmente naqueles voltados para a educação de crianças e adolescentes. Nesses textos, em geral, o conhecimento científico é apresentado como verdadeiro e definitivo, com base num pobre Método Científico ancorado num empirismo seguidor de regras bem estabelecidas.

Paul Feyerabend (1924-1996) destacava que o desenvolvimento da compreensão das ciências deveria incorporar "elementos pessoais e idiossincrasias coletivas" (Feyerabend, 1991, p. 101), preconizando uma aproximação entre ciência e arte, como se vê nesta citação:

se na verdade queres compreender as ciências, em vez de escrever sobre elas apenas histórias áridas e abstratas - e recorda que "compreender as ciências" significa, para mim, compreender tanto o contexto da descoberta como o da justificação -, então deves voltar-te para as artes e para as disciplinas humanísticas, o que significa que deves abandonar estas classificações artificiais de 
que estão cheias a maior parte das filosofias e das "narrativas racionais". Uma visão do mundo realmente compreensiva não pode de modo nenhum menosprezar os poetas... (Feyerabend, 1991, p. 105)

\section{Temas epistemológicos suscitados pela aproximação entre física e literatura}

Nessa linha de raciocínio, menciono a contribuição de um autor que, em diversos momentos de sua breve, conturbada e produtiva vida, mostrou ser um verdadeiro escritor com veia científica. Edgar Allan Poe (1809-1849) utilizou em muitos de seus contos conceitos físicos e matemáticos, como em "O mistério de Maria Roget" e "A carta furtada", nos quais o personagem central é provavelmente o primeiro detetive da ficção policial, C. Augusto Dupin.

Já no ensaio Eureka, seu último livro publicado em vida, escrito em 1847-1848, Poe apresentou um longo estudo sobre o método científico e sobre a teoria gravitacional de Isaac Newton, entre outros temas. Ele considerava esse seu ensaio-poema um texto metafísico e não um texto científico. Esse ensaio apresentava um depoimento sobre as contribuições metodológicas de Kepler, significativo na interpretação livre que faço da conceituação de perfil epistemológico de Bachelard. Em sua abordagem metodológica Poe criticava duramente a dedução aristotélica e a indução baconiana, propondo em seu lugar uma espécie de intuição que teria orientado a imaginação de Kepler e Newton:

Agora, garanto-lhe, da maneira mais positiva - continua tardar o progresso da verdadeira ciência, que realiza seus mais importantes avanços - como toda a história mostrará - por 'saltos' saltos, aparentemente intuitivos.

Não teria, especialmente, dado certo trabalho a esses fanáticos o determinar por qual de suas duas estradas foi atingida a mais importante e a mais sublime de todas as suas verdades - a verdade, o fato da gravitação? Newton deduziu-o das leis de Kepler ... Sim, Kepler adivinhou essas leis vitais - isto é, imaginou-as. Se lhe tivessem pedido que indicasse por qual estrada, se a dedutiva ou a indutiva, as havia ele atingido, sua resposta deveria ter sido: "Nada sei a respeito de estradas, mas conheço o mecanismo do Universo. Aqui está ele. Apoderei-me dele com minha alma. Alcancei-o simplesmente por meio da intuição" ... Sim! Kepler era essencialmente um teórico... (Poe, 1966, p. 456-61)

Assim, percebemos que o célebre autor de $O$ corvo tinha preocupações de natureza epistemológica. Embora insistisse que não pretendia fazer ciência, ele antecipa de forma metafórica a noção de 
ruptura epistemológica de Bachelard ao garantir que a ciência progride por 'saltos' intuitivos como lemos na primeira frase da citação. Já no início da segunda frase ele se refere ironicamente a Francis Bacon (1561-1626) que num aforismo dizia: “Só há e só pode haver duas vias para a investigação e para a descoberta da verdade" (Bacon, 1984, p. 16).

Poe foi influenciado pela metodologia nascida do sucesso das ciências físicas de sua época, demonstrando, segundo as palavras de Charles Baudelaire (1821-1867), uma aptidão científica que se traduz em sua guerra infatigável contra os falsos raciocínios (Poe, 1966, p. 47).

Analisando alguns de seus contos percebemos duas escolas filosóficas mencionadas por Bachelard: o empirismo claro e positivista e o racionalismo newtoniano ou kantiano. Como exemplo, apontarei trechos do conto "O mistério de Maria Roget", em que Poe narra comentários do detetive Dupin sobre argumentações da imprensa a respeito do momento em que o suposto cadáver de Maria Roget poderia ou não estar a flutuar, após ter sido jogado na água:

O primeiro objetivo do autor é mostrar-nos, pela brevidade do intervalo entre o desaparecimento de Maria e o encontro do cadáver a flutuar, que tal cadáver não pode ser o de Maria ... a gravidade específica do corpo humano, em sua condição natural, é quase igual à massa de água doce que ele desloca ... É evidente, contudo, que as gravidades do corpo e da massa de água deslocada são muito delicadamente equilibradas, e que uma ninharia pode fazer com que uma delas predomine. Um braço, por exemplo, erguido fora d'água e assim privado de seu equivalente é um peso adicional suficiente para imergir toda a cabeça, ao passo que a ajuda casual do menor pedaço de madeira habilitar-nos-á a elevar a cabeça, para olhar em derredor. (Poe, 1966, p. 377 e 379)

Os contos e novelas de Edgar Allan Poe são muito citados em livros da vertente poética de Bachelard, particularmente em "A água e os sonhos" e "O direito de sonhar". Nesses livros encontramos os quatro elementos gregos, revelando que Bachelard foi muito apegado ao campo tirando daí sua forte dependência dos elementos da natureza que alimentavam seu imaginário, sua racionalidade, seu devaneio e sua poética que tratam do fogo, da água, do ar, dos rios, das flores e da terra (Bachelard, 1997, p. 44).

Para os leitores de Poe não parecerá estranho que Bachelard tenha associado à água a imaginação material do poeta, como o conto aqui citado ilustra, além da profunda análise que o filósofo fez da novela As aventura de Gordon Pym, uma aventura fantástica de náufragos (Bachelard, 1997, p. 136-51).

Para explorar metaforicamente a mudança de perfil epistemológico sugerida pela leitura de Bachelard, retomo Emile Zola 
(1840-1902) e Fiódor Dostoiévski (1821-1881), este último influenciado também pela leitura de Poe. A ponte aqui será a transformação ocorrida na passagem da visão de mundo de Zola a Dostoiévski, em particular a ruptura epistemológica entre os escritos desses dois escritores.

Emile Zola enveredou pelo campo científico ao propor um novo papel para o romance. Para construir essa transformação no romance, ele inspirou-se no pensamento e na prática do médico e filósofo francês Claude Bernard (1813-1878) que pretendia, utilizando o desenvolvimento metodológico alcançado pela física e pela química, introduzir o estudo científico na medicina, então por ele considerada sob o domínio do pensamento conjetural e distante ainda da reflexão científica. Baseado no estudo desenvolvido pelo médico francês, Zola rompia com o que ele considerava o predomínio do idealismo no romance do século XIX, distante, portanto, da linguagem da ciência.

Tomando por referência romances de Stendhal (1793-1842), Honoré de Balzac (1799-1850) e Gustave Flaubert (1821-1880), Zola propôs uma revolução na estrutura do romance, introduzindo a forma por ele denominada romance experimental, fortemente influenciada pelo positivismo que marcava o campo científico de sua época:

A obra se torna uma ata; e nada mais; tem somente o mérito da observação exata, da penetração mais ou menos profunda da análise, do encadeamento lógico dos fatos ... uma única página de história humana, que tentou o romancista, da mesma forma que o estudo especial de um corpo pôde tentar um químico ... O papel estrito de um cientista é expor os fatos, ir até o fim da análise, sem arriscar-se na síntese; os fatos são estes, a experiência tentada em tais condições dá tais resultados; e ele aí se detém, porque, se quisesse avançar para além dos fenômenos, entraria na hipótese; seriam probabilidades, não seria ciência. Pois bem! O romancista deve igualmente ater-se aos fatos observados, ao estudo escrupuloso da natureza, se não quer perder-se em conclusões mentirosas. (Zola, 1982, p. 102-4)

Zola transportava o positivismo científico dominante nas ciências como orientação metodológica para a construção do romance. Se para Bachelard a "conduta da balança" marcava o empirismo ingênuo, a profissão de fé no determinismo clássico marcava os traços do perfil epistemológico do escritor francês.

Nesta aproximação entre ciência e literatura é marcante o romance póstumo e inacabado Bouvard e Pécuchet, onde Flaubert pretendia incluir uma enciclopédia do conhecimento do século XIX, da qual encontram-se fragmentos nas edições existentes da obra. Flaubert trabalhava com os dois personagens do título que, na ânsia de entender as peculiaridades da natureza, mergulham no 
estudo das diferentes áreas do conhecimento de sua época, passando a ler avidamente tratados de medicina, de geologia e de química, romances históricos e textos de psicologia. Fica evidente na leitura dos capítulos do romance que os dois, guiados pelos tratados desses diversos campos do conhecimento, se fiam no determinismo da ciência clássica. Como exemplo selecionei a seguinte passagem, com temas relacionados à astronomia:

Pécuchet prosseguiu:

- A velocidade da luz é de oitenta mil léguas por segundo. Um raio luminoso da Via-Láctea gasta seis séculos para chegar até nós. De sorte que é bem possível que uma estrela, quando a observamos, já tenha desaparecido. Muitas são intermitentes, outras não voltam jamais; e mudam de posição; tudo se agita, tudo passa.

- Entretanto, o Sol permanece imóvel!

- Outrora, era essa a crença; mas os sábios, hoje, declaram que ele se precipita para a constelação de Hércules!

Tais coisas perturbavam as idéias de Bouvard; depois de um minuto de reflexão, ele disse:

- A ciência baseia-se nos dados fornecidos pela apreciação de um determinado setor do espaço. Talvez não se aplique ao resto, muitíssimo maior, que se ignora e não se pode explorar. (Flaubert, 1981, p. 70)

Por essa mesma época, em 1875, era publicado no Brasil o romance $O$ doutor Benignus, do escritor português, naturalizado brasileiro, Augusto Emílio Zaluar (1825-1882), considerado o primeiro romance de ficção científica brasileiro. Nesse romance, inspirado em obras de Júlio Verne (1828-1905), Zaluar descrevia uma viagem do interior de Minas Gerais à Amazônia comandada pelo astrônomo e biólogo Dr. Benignus:

O Dr. Benignus resolveu, pois, consagrar-se inteiramente ao estudo das maravilhas astronômicas. Sendo o Sol o primeiro na grandeza e na ação que exerce sobre os outros mundos do sistema de que é o monarca fulgurante, entendeu que devia em primeiro lugar estudar a sua constituição física e a sua importância relativa na vasta amplidão do espaço celeste ...

- ... O meu fim único é estudar astronomia e resolver o problema da habitabilidade dos mundos. (Zaluar, 1994, p. 95 e 99)

Nesse romance, repleto de descrições da natureza, incidentes variados como a queda de um meteorito e um encontro com um balão tripulado, Zaluar expunha conhecimentos extraídos da física como aplicações da eletricidade e da espectroscopia, além de conheci- 
mentos da astronomia e de outras áreas científicas clássicas. Outro romance brasileiro que explora assuntos astronômicos é "Viagem ao céu", de Monteiro Lobato (1882-1948), publicado em 1932, onde Emília e seus companheiros fazem uma viagem pelo espaço sideral num texto recheado de conteúdo conceitual e de história da ciência.

Em contraponto a essa visão de mundo, ancorada no determinismo clássico, característico da mecânica newtoniana, ainda dominante à época de Zola e Zaluar, e numa espécie de antevisão daquilo que ocorreria a partir de 1905, com os trabalhos revolucionários da física contemporânea, particularmente os de Einstein, encontramos trabalhos de outros escritores que parecem prever o desenvolvimento científico que ainda estava por ocorrer. Entre os escritores do final do século XIX que exemplificam essa antecipação, menciono o russo Dostoiévski, que escreveu romances, novelas e contos nos quais o pensamento científico, mesmo que de forma metafórica, às vezes se apresenta na argumentação de seus personagens.

Dostoiévski foi muito além dos limites deterministas sugeridos por Zola na construção do romance experimental. Em inúmeras passagens de seu romance Os irmãos Karamazov, quando trata da problemática existencial enfrentada por seus personagens, o autor utiliza rudimentos de uma doutrina filosófica que estava muito além do determinismo positivista então dominante. Vários diálogos entre os irmãos Ivan e Aliócha permitem que Dostoiévski esboce, nesse romance publicado no ano em que nasceu Einstein, elementos da nova relação espaço-tempo que surgiria com a relatividade.

O historiador da ciência Boris Kuznetsov argumentava que Dostoiévski formulou através de seus romances perguntas filosóficas que seriam respondidas por Einstein através de suas teorias físicas. Segundo o historiador, Einstein teria afirmado seu débito intelectual para com o autor russo com as seguintes palavras: "Dostoiévski oferece-me mais que qualquer outro pensador, mais que Gauss" (Kuznetsov, 1972, p. 59).

$\mathrm{O}$ autor utilizava argumentos geométricos compatíveis com a nova visão de mundo oferecida pela física relativística. Eis um breve trecho de "Os irmãos Karamazov" onde esse pensamento é exemplificado:

É preciso notar, no entanto, que, se Deus existe, se criou verdadeiramente a terra, fê-la, como se sabe, segundo a geometria de Euclides, e não deu ao espírito humano senão a noção das três dimensões do espaço.

Entretanto, encontraram-se, encontram-se ainda geômetras e filósofos, mesmo eminentes, para duvidar de que todo o universo e até mesmo todos os mundos tenham sido criados somente de 
acordo com os princípios de Euclides. Ousam mesmo supor que duas paralelas que, de acordo com as leis de Euclides, jamais se poderão encontrar na terra, possam encontrar-se, em alguma parte, no infinito. Decidi, sendo incapaz de compreender mesmo isto, não procurar compreender Deus. Confesso humildemente minha incapacidade em resolver tais questões; tenho essencialmente o espírito de Euclides: terrestre. De que serve querer resolver o que não é deste mundo? E aconselho-te a jamais quebrar a cabeça a respeito, meu amigo Aliócha, sobretudo a respeito de Deus: existe ele ou não? Essas questões estão fora do alcance dum espírito que só tem a noção das três dimensões ... Que as paralelas se encontrem sob meus olhos, verei e direi que se encontraram; e no entanto não o admitirei. Eis o essencial, Aliócha, eis minha tese. (Dostoiévski, 1971, p. 177)

Kuznetsov entendia que Dostoiévski partia da fé tradicional e 'euclidiana' na harmonia providencial, mas não podia, como artista que submetia seus personagens ao enfrentamento do real, ignorar a harmonia 'não-euclidiana'. Embora o pensador preferisse a fé euclidiana, o artista não podia ter apenas essa crença, "a lógica da arte criativa era irreversível" e Dostoiévski não podia deixar de ser um 'rebelde' (Kuznetsov 1972, p. 51). Por conta desse posicionamento ocorre a rejeição da harmonia 'não-euclidiana' por parte da mente 'euclidiana' de Ivan Karamazov. Dostoiévski levava o confronto de idéias até as últimas conseqüências, isto é, até o rompimento com o ideário defendido pelo 'criador' de tais personagens. Pode-se fazer aqui um paralelo com a 'ruptura epistemológica' formulada por Gaston Bachelard.

Dessa forma, muito antes de 1905, a cultura representada pelo novo espírito científico descrito por Bachelard já marcava metaforicamente o perfil epistemológico desse intelectual-escritor com veia científica. A aproximação entre as questões artísticas, formuladas pelo escritor russo, e as possíveis respostas científicas, elaboradas por Einstein, corresponde a um diálogo entre os conceitos científicos e as imagens poéticas, elementos presentes na obra de Bachelard.

Creio ter ilustrado com esses exemplos que a ruptura epistemológica bachelardiana, interpretada aqui de uma forma mais livre, também pode ser detectada em obras literárias, permitindo uma ponte entre esses dois campos do conhecimento e entre essas duas práticas tradi-cionalmente distanciadas em nosso imaginário e em nossas escolas.

Como outro exemplo do que denomino elementos do 'perfil epistemológico' de Dostoiévski, menciono o estudo sobre o conto “O senhor Prokhartchin", elaborado pelo professor Boris Schnaiderman, estudioso e tradutor brasileiro da literatura russa. De forma semelhante a Kuznetsov, Schnaiderman conclui que o escritor russo não procurava afirmar sua ideologia por meio de seu conto, mas colocava 
seus personagens numa situação experimental, embora rompendo com a concepção epistemológica presente em Zola.

Esse conto foi escrito cerca de sessenta anos antes da Teoria da Relatividade Restrita de Einstein. Se na saga dos Karamazov é destacada a presença da geometria não-euclidiana, em "O senhor Prokhartchin" o autor russo já vincula fortemente os momentos culminantes da existência de seus personagens com o espaço-tempo em que as diferentes ações têm lugar.

Depois de discorrer sobre os diferentes tempos que comparecem no conto como o tempo de Prokhartchin, o tempo dos inquilinos, o tempo cronológico, o tempo psicológico, o tempo do leitor, o tempo da narrativa, Schnaiderman sugere que "certas concepções que se tornaram correntes graças à física moderna iluminam de modo peculiar este conto, tornam-no bem menos misterioso e 'confuso', mais próximo de nós do que era para seus contemporâneos" (Schnaiderman, 1982, p. 92).

A problemática do tempo relativístico impregnando o cenário literário é muito controversa e rica de possibilidades. Adentrando a produção literária do século $X X$, notamos que o campo de análise se amplia. Ao longo desse século encontramos vários exemplos da influência dos trabalhos de Einstein na literatura. De meu conhecimento posso nomear James Joyce (1882-1941), Thomas Mann (18751955), William Faulkner (1897-1962), Charles Percy Snow (19051980) e Friedrich Dürrenmatt (1921-1990).

O físico e historiador da ciência Gerald Holton, um dos criadores do projeto Harvard de ensino de física de meados do século passado, que utilizava a história da ciência e a ponte da física com a cultura geral, analisa também a relação entre a física de Einstein e a literatura. Holton criticava muitos escritores, pintores e críticos de arte que interpretavam alguns trabalhos artísticos como impregnados pela física relativística, como seria o caso das análises de alguns quadros de Pablo Picasso (1881-1973) e Marcel Duchamp (1887-1968). Ele também criticava Jean-Paul Sartre quando este afirmava que "a teoria da relatividade se aplica no todo à ficção" (Holton, 1995, p. 9).

No entanto, Holton dá como exemplo do que ele considera uma boa utilização da relatividade de Einstein o romance $O$ som e a fúria, de William Faulkner, mostrando que ele não rejeita a possibilidade de escritores usarem, como inspiração para elucidar a trama vivida por seus personagens, seu conhecimento sobre as teorias científicas (Holton, 1995, p. 10).

Quando li esse romance de Faulkner ficou-me a lembrança das desavenças da família Compson, que vivia no decadente Sul dos Estados Unidos, narradas num formato extremamente complexo, especialmente por causa das rupturas cronológicas de eventos que ocorreram em 1910 e 1928. Embora fosse evidente a problemática relação de Quentin Compson com relógios e com o tempo, eu não 
havia percebido a forte presença da relatividade de Einstein como Holton o faz.

Holton destaca o segundo capítulo do romance, aquele que mais me impressionou. A ação se passa em 2 de junho de 1910, e nela é narrada a luta de Quentin com o fluir inexorável do tempo e sua incestuosa culpa associada ao amor platônico pela irmã Candace, que acaba levando-o ao suicídio. Eis alguns trechos representativos da relação tensa de Quentin com o tempo e os relógios, escolhidos da minha leitura desse capítulo:

Encontrava-me então no tempo e ouvia o relógio. Era do Avô e, ao dar-mo, meu Pai disse: - ... Dou-to não para que te lembres de tempo, mas para que o possas esquecer ... Não creio que alguém tenha jamais deliberadamente escutado um relógio.

... peguei no relógio ... e, torcendo os ponteiros, pu-los também no cinzeiro.

... Havia cerca de uma dúzia de relógios na montra, uma dúzia de horas diferentes e todas com a mesma dogmática e contraditória segurança que o meu tinha, sem ponteiros. A contradizerem-se uns aos outros. (Faulkner, 1969, p. 95, 99 e 103)

Poderia ter escolhido outros trechos desse e de outros capítulos com passagens sobre o tempo e outras menções a fenômenos físicos, mas isso não daria uma idéia da complexidade utilizada por Faulkner na construção de seu romance. Concordo com Holton quando afirma que o dilema do escritor era entender "o que havia sido deixado para ele: tempo e espaço são então sem sentido; tal é a viagem através deles; assim é a dor mesma, quando os próprios deuses estão jogando jogos de azar, e todo o som e a fúria significam nada" (Holton, 1995, p. 12).

E a saída desse dilema seria o poeta procurar captar a estrutura construída pela nova visão de mundo associada à ciência, fundindoa com sua imaginação literária, mesmo que utilizando uma pálida noção das idéias científicas. Essas idéias são usadas metaforicamente para construir uma nova mistura que não estava lá antes (Holton, 1995, p. 12-3).

Vale a pena complementar esses breves comentários sobre o romance de Faulkner com uma observação de Jean-Paul Sartre, um dos autores criticados por Holton, como já mencionei:

Quando se lê "O som e a fúria", a primeira coisa que chama a atenção são as bizarrias da técnica. Por que é que Faulkner fragmentou o tempo da sua história e baralhou os bocados? ... uma técnica romanesca leva-nos sempre à metafísica do romancista. A tarefa do crítico consiste em descobrir esta antes de apreciar aquela. Ora, salta aos olhos que a metafísica de Faulkner é uma metafísica do tempo. (Sartre, 1968, p. 62-3) 
Notamos, assim, como é rica a busca por temas epistemológicos suscitados pela aproximação entre física e literatura. Bachelard, ao descrever as escolas filosóficas que compõem o quadro do perfil epistemológico acrescenta, inspirado nos trabalhos dos poetas surrealistas, para além do racionalismo clássico, o surracionalismo, o racionalismo surrealista. Assim, considero apropriado encerrar esta seção com uma citação do poeta e escritor surrealista André Breton que, ao tomar conhecimento, no início da década de 1930, da utilização por Bachelard de argumentos baseados no seu "Manifesto do surrealismo", escreveu:

A introdução recente, pelo senhor Gaston Bachelard, no vocabulário científico da palavra 'surracionalismo' que aspira a dar conta de todo um método de pensamento, confere uma atualidade e um vigor suplementar à palavra 'surrealismo', cuja aceitação até agora havia sido estritamente artística. Uma vez mais um dos termos verifica ao outro: esta comprovação basta para pôr em evidência o espírito comum, fundamental, que anima em nossos dias às investigações do homem, já se trate do poeta, do pintor ou do cientista. (Breton, 1996, p. 115, minha tradução)

\section{À guisa de conclusão}

Os romancistas e contistas mencionados neste texto não tiveram formação básica em física. No entanto, quase todos experimentaram algo dessa ciência. Poe, quando trabalhou como jornalista em um jornal literário de Richmond, entre 1835 e 1837, escrevia resenhas até mesmo de livros de física e de outros temas científicos que, segundo Baudelaire, demonstravam sua aptidão para a ciência. Zola sofreu a influência da filosofia determinista de Claude Bernard, como já destaquei. Dostoiévski chegou a estudar engenharia militar contra sua vontade, e nessa época deve ter tido algum contato com conhecimentos elementares de física e rudimentos da geometria não-euclidiana. Holton lembra que na década de 1920, ao final da qual Faulkner escreveria O som e a fúria, o romancista deveria ter lido textos sobre a relatividade, muito presente no cotidiano da imprensa americana naqueles anos. Certamente algo dessa natureza é válido também para os demais escritores mencionados, mesmo os brasileiros. Mas todos eles eram leitores vorazes da grande literatura de sua época.

Em 1998, inspirado pela experiência desses escritores, apresentei uma comunicação oral, num encontro de pesquisa em ensino de física, que tinha por título: "Ensino de física através de sua história e filosofia para quem gosta de literatura". A preocupação com a aproximação entre as duas culturas também estava presente nos países desenvolvidos, como exemplificado num trabalho que buscava pesquisar as maneiras pelas quais cursos de humanidades, 
que contemplavam a leitura de poemas, poderiam ser úteis para estudantes de física que normalmente fugiam de tais cursos (Tobias \& Abel, 1990).

Recentemente numa apresentação de um livro, parafraseando Friedrich Engels, Michael Löwy escreveu que "as grandes obras literárias nos ensinam mais sobre a sociedade em que vivemos do que uma tonelada de manuais de economia ou de sociologia" (Löwy, 2005). As grandes obras literárias, algumas delas mencionadas neste artigo, não poderiam, portanto, servir de convite para apreender algo sobre a física e sua epistemologia cambiante ao longo do tempo, mesmo para aqueles indivíduos que dizem detestar as ciências?

Acredito que a física, bem como as outras ciências, bem trabalhada na escola, pode muito bem ser um instrumento útil tanto para o pensador diurno, dominado pelo pensamento e discurso racionais, quanto para o pensador noturno, marcado pelo pensamento imaginário e sonhador. A grande ciência, que nos seus momentos criativos de ruptura nasce do encontro dessas duas vertentes, tem tudo para satisfazer o pensador que apela para o fantástico, para a imaginação, para o vôo do espírito. Precisamos construir a ponte entre as duas culturas como sugerida ironicamente por Dostoiévski:

- Eh, senhores, como é que se pode ter, no caso, sua própria vontade, quando se trata da tabela e da aritmética, quando está em movimento apenas o dois e dois são quatro? Dois e dois são quatro mesmo sem a minha vontade...

... Estou de acordo em que dois e dois são uma coisa admirável; mas, se é para elogiar tudo, então dois e dois são cinco também constitui, às vezes, uma coisinha muito simpática. (Dostoiévski, 2004, p. 45 e 47)

\section{REFERÊNCIAS BIBLIOGRÁFICAS}

Bachelard, Gaston 1972

Bachelard, Gaston 1997

Bacon, Francis 1984

Ball, Philip

2002

Breton, André 1996

Bronowski, Jacob 1998

Dostoiévski, Fiódor Mikhailovitch 2004
Filosofia do novo espírito científico (A filosofia do não).

Lisboa: Presença.

El derecho de soñar.

México: Fondo de Cultura Económica.

Novum organum.

3. ed. São Paulo: Abril Cultural.

Beyond words: science and visual theatre. Interdisciplinary Science Review, v. 27, n. 3, p. 169-72.

Antologia (1913-1966).

10. ed. México: Siglo Veintiuno Ed.

O olho visionário.

Ensaios sobre arte, literatura e ciência. Brasília: Ed. UnB.

Memórias do subsolo.

5. ed. São Paulo: Ed. 34. 
Dostoiévski,

Fiódor Mikhailovitch

1971

Faulkner, William 1969

Feyerabend, Paul 1991

Flaubert, Gustave 1981

Holton, Gerald 1995

Kuznetsov, Boris 1972

Löwy, Michael 2005

Martins, Roberto de Andrade 2005

Moreira, Ildeu de Castro 2002

Pinto, Alexandre Custódio 2003

Poe, Edgar Allan 1966

Sartre, Jean-Paul 1968

Schnaiderman, Boris 1982

Snow, Charles Percy 1997

Snyders, Georges 1993

Tobias, Sheila; Abel, Lynne S.

1990

Zaluar, Augusto Emílio 1994

Zanetic, João 2006

Zanetic, João 2005

Zola, Emile 1982
Os irmãos Karamázov.

São Paulo: Abril Cultural.

O som e a fúria.

2. ed. Lisboa: Portugália.

Diálogo sobre o método.

Lisboa: Presença.

Bouvard e Pécuchet.

Rio de Janeiro: Nova Fronteira.

Einstein's influence on our culture. In: Einstein history, and other passions. New York: American Institute of Physics Press. p. 3-21.

Einstein and Dostoievski. A study of the relation of modern physics to the main ethical and aesthetic problems of the nineteenth century.

London: Hutchinson Educational.

Apresentação. In: Coutinho, Carlos Nelson. Lukács, Proust e Kafka.

Rio de Janeiro: Civilização Brasileira.

Física e história.

Ciência e Cultura, São Paulo, v. 57, n. 3, p. 25-9.

Poesia na sala da aula de ciências?

Física na Escola, São Paulo, v. 3, n. 1, p. 17-23.

Tradição cultural, contraste entre teorias e ensino de física.

São Paulo, Dissertação de Mestrado, Ifusp/Feusp.

Poesia e prosa: obras escolhidas.

Rio de Janeiro: Ed. de Ouro.

A propósito de "O Som e a Fúria". A temporalidade em Faulkner. In: Situações I. Lisboa: Europa-América.

Dostoiévski prosa poesia.

São Paulo: Perspectiva.

As duas culturas.

São Paulo: Edusp.

Alunos felizes: reflexão sobre a alegria na escola a partir de textos literários. São Paulo: Paz e Terra.

Poetry for physicists.

American Journal of Physics, v. 58, n. 9, p. 816-21.

O doutor Benignus.

Rio de Janeiro: Ed. UFRJ.

Física e arte: uma ponte entre duas culturas.

Pro-Posições, v. 17, n. 1 (49), jan./abr., p. 39-57.

Física e cultura.

Ciência e Cultura, São Paulo, v. 57, n. 3, p. 21-4.

O romance experimental e o naturalismo no teatro.

São Paulo: Perspectiva.

Recebido para publicação em outubro de 2005.

Aprovado para publicação em fevereiro de 2006. 